\title{
Synthesis, Characterization and Radiolabeling of Bortezomib with ${ }^{99 \mathrm{~m}} \mathrm{TC}$
}

\author{
Ravi Ranjan Kumar ${ }^{1,2}$, Devinder Kumar Dhawan ${ }^{2}$, Anshoo Malhotra ${ }^{1, *}$ \\ ${ }^{1}$ Department of Biophysics, Post Graduate Institute of Medical Education and Research (PGIMER), Chandigarh, India \\ ${ }^{2}$ Centre for Nuclear Medicine, Panjab University, Chandigarh, India
}

\author{
Email address: \\ anshoo.malhotra@gmail.com (A. Malhotra)
}

\section{To cite this article:}

Ravi Ranjan Kumar, Devinder Kumar Dhawan, Anshoo Malhotra. Synthesis, Characterization and Radiolabeling of Bortezomib with ${ }^{99 \mathrm{~m}} \mathrm{TC}$. European Journal of Biophysics. Special Issue: Recent Perspectives in Biophysics. Vol. 3, No. 3-1, 2015, pp. 11-14.

doi: $10.11648 /$ j.ejb.s.2015030301.12

\begin{abstract}
The development of new specific diagnostic radiopharmaceutical is the need of the hour for the timely management of cancer patients. At present, available radiopharmaceuticals are not much specific for tumor imaging. The present study was conducted to radiolabel bortezomib with technetium-99m $([99 \mathrm{~m}] \mathrm{Tc})$. Labelling was performed by both direct as well as indirect methods and the developed radiotracer was subjected to quality control tests. The labelling efficiency of $[99 \mathrm{~m}]$ Tc-bortezomib was estimated to be more than $39 \%$. with direct method. On the other hand, indirect method using protein albumin as ligand resulted in net binding of $41 \%$. The present study resulted in successfully labelling of target specific anticancer drug Bortezomib by both direct as well as indirect methods. This newly developed radiotracer has promising avenues for early detection of deadly disease of cancer. The radiotracer, however, needs further validation through animal experimentation and clinical studies.
\end{abstract}

Keywords: Bortezomib, Albumin, Direct Labelling, Indirect Labelling, ${ }^{99 \mathrm{~m}} \mathrm{TC}$

\section{Introduction}

Cancer is a class of diseases which involve uncontrolled division of cells. These cells have ability to invade nearby tissue by the process of invasion or get disseminated to distant locations by the process of metastasis which involves transport of cancerous cells to distant sites via bloodstream/ lymphatic system. Extensive research is going on worldwide to find various therapies and early diagnostic measures to cure this pathological state. However to date, the success rate is not up to the satisfactory level. So, it is desired to develop a target specific screening agent which is able to detect the process of carcinogenesis right at the initiation stage

Targeted therapy is the focus of the cancer research worldwide (1). It is a type of medication that blocks the growth of cancer cells by interfering with specific targeted molecules needed for carcinogenesis and tumor growth, rather than by simply interfering with rapidly dividing cells (e.g. with traditional chemotherapy). Targeted cancer therapies are believed to be more effective than current treatments and also less harmful to normal cells.

In the present study, the drug of interest is bortezomib which belongs to a group of target specific anti cancer drugs and is a highly selective, reversible inhibitor of the $26 \mathrm{~S}$ proteasome in cancer cells (2). The proteasome is an ubiquituous enzyme complex that plays a critical role in the degradation of many proteins involved in cell cycle regulation, apoptosis and angiogenesis (3). In cancer cells, these pathways are excessively expressed and are elementary for cell survival as well as proliferation, so the inhibition of proteasome is an attractive potential anticancer therapy $(4,5)$. On the other hand, albumin is the bio-olecule of interest in the present study which is an endogenous nano-particle and is known for its binding properties to various endogenous metabolites, drugs and metal ions. Therefore, the prime aim of the present study is to radio label Bortezomib with ${ }^{99 \mathrm{~m}} \mathrm{Tc}$ so as to develop a new radiopharmaceutical which will act as promising diagnostic agent to detect the process of carcinogenesis at an early stage. So, the present study is first of its kind to label a target specific anticancer drug bortezomib with ${ }^{99 \mathrm{~m}} \mathrm{Tc}$ by both direct as well as indirect labeling. 


\section{Materials and Methods}

\subsection{Chemicals}

Bortezomib was purchased from Cadila pharmaceuticals ltd. All other reagents were procured from Merck Chemicals and Loba chemicals Pvt. Ltd.

\subsection{Labelling Procedures}

Direct labelling approach: This approach involed use of radioisotope, drug of interest and an effective reducing agent. For direct labelling of Bortezomib with $99 \mathrm{mTc}$, stannous chloride was used as reducing agent. Fresh pertechnetate $([99 \mathrm{~m}] \mathrm{TcO} 4 \quad-)$ eluted from ([99]Molybdenum[99m]Technetium Column Generator (Isorad, Israel) was used for the labelling procedures. The variable concentrations $(20 \mathrm{lg}, 50 \mathrm{lg}, 100 \mathrm{lg}, 200 \mathrm{lg}, 400 \mathrm{lg}$, and $1000 \mathrm{lg}$ ) of stannous chloride ( $\mathrm{Sncl}(2) .2 \mathrm{H}(2) \mathrm{O})$, different $\mathrm{pH}(2-9)$ conditions, and variable incubation times ( 5 minutes, 10 minutes, 20 minutes, and 30 minutes) were tested. [99m]Tc-doxorubicin was prepared by dissolving $2 \mathrm{mg}$ of doxorubicin in $1 \mathrm{~mL}$ distilled water followed by addition of a standardized concentration of $100 \mathrm{lg}$ stannous chloride dihydrate and $\mathrm{pH}$ was marked to 6.0. The contents were filtered through a $0.22 \mathrm{~lm}$ membrane filter (Millipore) into a sterile vial. About $40.0 \mathrm{MBq}$ radioactivity of pertechnetate was added to the mixture and incubated for 15 minutes. The resultant radioligand $[99 \mathrm{~m}] \mathrm{Tc}$-doxorubicin was then subjected to various quality control tests.

Indirect labelling: This approach involved use of additional ligand so as to assist in binding of both the drug of interest and radioisotope. In the present study, we have used albumin as ligand as it has ability to bind both the Bortezomib as well as $99 \mathrm{mTc}$.

\subsection{In Vitro Quality Control Procedures}

For quality control two methods were used viz. Paper chromatography and Instant thin layer chromatography.

Paper Chromatography: Placed approximately $1 \mathrm{ml}$ of acetone into one $10-\mathrm{mI}$ glass vial and $1 \mathrm{ml}$ of $0.9 \% \mathrm{NaCI}$ into an identical vial. Loaded a spot of radiopharmaceutical at the bottom of the Whatman paper chromatography strip and marked the position of the same with a pencil line. Developed paper strip in acetone solution for free pertechnate and in $0.9 \% \mathrm{NaCI}$ solvent for free hydrolyzed Tc, until solvent front migrated to top. Cut strips into sections. Counted all sections for activity (per unit time) using a gamma counter.

Instant Thin Layer Chromatography: Radiochemical purity of the labeled complex was determined by instant thin layer chromatography (ITLC) using 100\% acetone and $0.9 \%$ sodium chloride as solvents. Briefly, $20.0 \mathrm{lL}$ of radiocomplex was dropped onto the ITLC strip at the marked origin point and put into the solvent chamber at room temperature. The percent labeling of [99m]Tc-bortezomib was calculated at 15 minutes, 1 hour, 4 hours, and 24 hours by ITLC method. The percentage of free pertechnetate, hydrolyzed pertechnetate, and bound pertechnetate was calculated.

\section{Results}

The results obtained from various experiments conducted in this study are depicted in Tables

\subsection{Standardization of Stannous Chloride Concentration}

In order to label the drug we first standardized concentration of reducing agent viz. Stannous chloride via keeping the drug concentration constant at $10 \mu \mathrm{g}$. We incubated different concentrations of stannous chloride with drug and 2 mili curie of radioisotope $99 \mathrm{mTc}$ at room temperature for 10 minutes. Then ran paper/ ITLC chromatography. We used two different solvents in order to evaluate percentages of $99 \mathrm{mTc}$ impurities called free pertechnetate and hydrolyzed $99 \mathrm{mTc}$. Table a gives information about free pertechnetate using acetone as solvent and table $b$ gives information about hydrolyzed $99 \mathrm{mTc}$. Table c gives net percentage labelling which is $38 \%$ and the best dose standardized for stannous chloride is $10 \mu \mathrm{g}$.

Table a. Standardization of concentration of reducing agent stannous chloride in acetone.

\begin{tabular}{llll}
\hline $\begin{array}{l}\text { Sn+2 } \\
\text { (micro gram) }\end{array}$ & $\begin{array}{l}\text { Drug } \\
\text { (microgram) }\end{array}$ & $\begin{array}{l}\text { Net Free } \\
\text { Counts=Free } \\
\text { cts/Total cts. }\end{array}$ & $\begin{array}{l}\text { (\%) Free } \\
\text { pertechnetate }\end{array}$ \\
\hline 10 & 10 & $.0456(774 / 16946)$ & 4.56 \\
30 & 10 & $.056(157 / 2786)$ & 5.6 \\
50 & 10 & $.0109(21 / 1926)$ & 1.09 \\
100 & 10 & $.0606(162 / 2670)$ & 6.06 \\
\hline
\end{tabular}

Table b. Standardization of concentration of reducing agent stannous chloride in saline.

\begin{tabular}{llll}
\hline $\begin{array}{l}\text { Sn+2 } \\
\text { (micro } \\
\text { gram) }\end{array}$ & $\begin{array}{l}\text { Drug } \\
\text { (micro gram) }\end{array}$ & $\begin{array}{l}\text { Net Hydrolysed } \\
\text { Counts=Hydrolysed } \\
\text { cts/Total cts. }\end{array}$ & $\begin{array}{l}\text { (\%) } \\
\text { Hydrolysed Tc }\end{array}$ \\
\hline 10 & 10 & $.56(3309 / 5837)$ & 56.6 \\
30 & 10 & $.9563(2102 / 2198)$ & 95.6 \\
50 & 10 & $.985(1390 / 1411)$ & 98.5 \\
100 & 10 & $.9306(1408 / 1513)$ & 93.06 \\
\hline
\end{tabular}

Table $\boldsymbol{C}$. Net binding percentage.

\begin{tabular}{lll}
\hline $\begin{array}{l}\text { Sn+2 (micro } \\
\text { gram) }\end{array}$ & Drug (micro gram) & $\begin{array}{l}\text { Net Binding \%=100- } \\
(\% \text { Free+\%Hydrolysed) }\end{array}$ \\
\hline 10 & 10 & 38 \\
30 & 10 & 00 \\
50 & 10 & .4 \\
100 & 10 & .8 \\
\hline
\end{tabular}

Table d. Standardization of concentration of drug chloride in acetone.

\begin{tabular}{llll}
\hline $\begin{array}{l}\text { Sn+2 } \\
\text { (microgram) }\end{array}$ & $\begin{array}{l}\text { Drug } \\
\text { (microgram) }\end{array}$ & $\begin{array}{l}\text { Net free } \\
\text { counts=Free } \\
\text { cts/Total cts }\end{array}$ & $\begin{array}{l}\text { (\%) Free } \\
\text { pertechnetate }\end{array}$ \\
\hline 10 & 20 & $.032(4545 / 141889)$ & 3.2 \\
10 & 30 & $.022(5447 / 242617)$ & 2.2 \\
10 & 40 & $.018(3773 / 203325)$ & 1.8 \\
\hline
\end{tabular}


Table e. Standardization of concentration of drug chloride in saline.

\begin{tabular}{llll}
\hline $\begin{array}{l}\text { Sn+2 } \\
\text { (microgram) }\end{array}$ & $\begin{array}{l}\text { Drug } \\
\text { (microgram) }\end{array}$ & $\begin{array}{l}\text { Net Hydrolysed } \\
\text { counts=Hydrolysedets/ } \\
\text { Total cts }\end{array}$ & $\begin{array}{l}\text { \%Hydrolyse } \\
\text { d Tc }\end{array}$ \\
\hline 10 & 20 & $.774(102714 / 132650)$ & $77 . .4$ \\
10 & 30 & $.961(131766 / 137090)$ & 96.1 \\
10 & 40 & $.706(217608 / 307917)$ & \\
\hline
\end{tabular}

\subsection{Standardization of Bortezomib Drug Concentration}

We then standardized the dose concentration of Bortezomib drug Table $\mathrm{f}$ gives net percentage labelling which is $27.6 \%$ and the best concentration observed in this experiment was $40 \mu \mathrm{g}$. However, we have got better binding with $10 \mu \mathrm{g}$ of drug in earlier experiment. So the final standardized concentration for drug is $10 \mu \mathrm{g}$.
Table f. Net Binding Percentage.

\begin{tabular}{lll}
\hline Sn(microgram) & Drug(microgram) & $\begin{array}{l}\text { \% Net Binding=100- } \\
\text { (\%Free+\%Bound) }\end{array}$ \\
\hline 10 & 20 & 19.4 \\
10 & 30 & 1.7 \\
10 & 40 & 27.6 \\
\hline
\end{tabular}

\subsection{Standardization of Albumin Concentration (Indirect Lableing)}

To further improve the labelling efficiency we used albumin as ligand. Similarly we standardized the concentration of albumin by keeping concentration of the drug as well as stannous chloride constant at $10 \mu \mathrm{g}$ So final standardized concentration for albumin for drug is $10 \mu \mathrm{g}$ (Table g).

Table g. Standardization of albumin concentration (Indirect lableing)

\begin{tabular}{llllll}
\hline $\mathrm{Sn}^{2+}$ & Drug & Albumin & \%Free $\left({ }^{99 m}\right.$ TcO4-) & \%Hydrolysed( ${ }^{99 m}$ TcO $\left._{2}\right)$ & Net Binding \% \\
\hline 10 & 10 & 40 & 1.85 & 73.3 & 24.7 \\
10 & 10 & 20 & 18 & 60 & 22 \\
10 & 10 & 10 & 4.7 & 54.0 & 41.3 \\
\hline
\end{tabular}

\section{Discussion}

The present study was aimed to develop such a radiopharmaceutical which is able to detect the process of carcinogenesis at an early stage. We have utilized drug delivery efficacy of nano systems (albumin in indirect labeling), sensitivity of radionuclide $\left({ }^{99 \mathrm{~m}} \mathrm{Tc}\right)$ and target specific ability of bortezomib (6-7). The combined utilization or in other words fusion of these promising areas resulted in successful development of a unique radiopharmaceutical which will allow early detection of process of carcinogenesis.

Direct labelling approach does not require any additional ligand or any other assistance by foreign molecule. It involves use of radioisotope, drug of interest and an effective reducing agent. In the present study, stannous chloride was used as reducing agent for the direct labelling of Bortezomib with $99 \mathrm{mTc}$. We tested various concentrations of both stannous chloride and drug, in order to achieve labelling with high efficiency. In nuclear medicine, the process of labeling of cells and molecules with Technetium-99m almost always requires the use of a reducing agent, since the eluate obtained in the generator as pertechnetate ion is not easily connect to other chemical species (8).

Indirect labelling, on the other hand involved utilization of additional ligand so as to assist in binding of both the drug of interest and radioisotope. In the present study we have used albumin as ligand as it has ability to bind both the Bortezomib as well as $99 \mathrm{mTc}$. With indirectly we are able to further enhance the labelling efficiency of bortezomib with ${ }^{99 \mathrm{~m}} \mathrm{Tc}$. The serum albumin is a an endogenous nano-particle having a molecular mass of $66 \mathrm{KD}$ with molecular dimensions of $30 \times 30 \times 80 \mathrm{~A}^{0}(3 \times 3 \times 8 \mathrm{~nm})$ and is known for its binding properties to various endogenous metabolites, drugs and metal ions (9). The serum albumin is an efficient nano sized drug delivery system which can be exploited for the preferential and specific target oriented drug delivery. The main mechanism of the above albumin transport is transcytosis, which is a molecular pathway that involves interaction of albumin with its cell surface albumin receptor known as gp60 (albodin). Some studies have reported that the metabolism, body distribution and efficacy of various drugs markedly become affected after binding with albumin (1011). Also, there is a recent report which revealed the binding abilities of Bortezomib drug with albumin (3). Binding was for both the methods were further confirmed by paper as well as instant thin layer chromatographic (ITLC) procedures as they are the preferred choice of for quick as well as efficient quality contol of the newly formed radiopharmaceuticals (12).

So, the present study concludes that target specific anticancer drug Bortezomib is labelled more efficiently with indirect method of radio-labelling using albumin as a ligand. This newly developed radiotracer has promising avenues for early detection of deadly disease of cancer. Further, investigations are needed for clinical validation via experimental as well as clinical studies.

\section{Acknowledgements}

We are very thankful to Science and Engineering Research Board (SERB), Department of Science and Technology, Govt. of India for the financial assistance for the above project.

\section{References}

[1] Gerber DE. Targeted Therapies. American Family Physician 2008 77(3): 311-319. 
[2] Bonvini P, Zorzi E, Basso G, Rosolen A. Bortezomibmediated $26 \mathrm{~S}$ proteasome inhibition causes cell-cycle arrest and induces apoptosis in CD-30+ anaplastic large cell lymphoma. Leukemia 2007; 21 (4): 838-42.

[3] Feng-Ting Liu, Samir G, Agrawal I Zanyar Movasaghi et al. Dietary flavonoids inhibit the anticancer effects of the proteasome inhibitor bortezomib. Blood 2008;112(9): 38353846.

[4] Montagut C, Rovira A, Albanell J. The proteasome: a novel target for anticancer therapy. Clinical Translational Oncology 2006; 8(5):313-7.

[5] Rajkumar SV, Richardson P, Hideshima T. Proteasome inhibition as a novel therapeutic target in human cancer. Journal of Clinical Oncology 2005; 23:630-9.

[6] Mujtaba T, Dou QP.Advances in the understanding of mechanisms and therapeutic use of bortezomib. Discov Med. 2011 Dec;12(67):471-80.

[7] Cvek B. Proteasome inhibitors. Prog Mol Biol Transl Sci. 2012;109:161-226.
[8] Costa DL. Albuquerque AC, Camacho ACLF, Costa FCH. Studying Of The Biological Effects Of Stannous Chloride On The Cell Membrane. New York Science Journal 2010;3(7).

[9] Carter and Ho, Structure of serum albumin. Adv Protein Chem 45 (1994) 153-203.

[10] Gradishar WJ, Tjulandin S, Davidson N, Shaw H, Desai N, Bhar P, et al. Phase III trial of nanoparticle albumin-bound paclitaxel compared with polyethylated castor oil-based paclitaxel in women with breast cancer. J Clin Oncol. 2005;23:7794-7803.

[11] Desai N, Trieu V, Yao Z, Louie L, Ci S, Yang A, et al. Increased antitumor activity, intratumor paclitaxel concentrations, and endothelial cell transport of cremophorfree, albumin-bound paclitaxel, ABI-007, compared with cremophor-based paclitaxel. Clin Cancer Res. 2006;12:13171324.

[12] KumarP, Singh B, Sharma S, Mittal BR. Evaluation of [99m]Tc-Labeled Doxorubicin as a Potential Scintigraphic Probe for Tumor Imaging. Cancer Bio and radiophar 2012;27(3): 221-26. 